\title{
MITOS DE ORIGEM DE POVOS ORIGINÁRIOS, EU- ROPEUS E JUDAICO-CRISTÃOS: UM EXERCÍCIO DE ANÁLISE
}

\section{ORIGINAL, EUROPEAN AND JEWISH-CHRISTIAN PEOPLES ORIGIN MYTHS: AN EXERCISE OF ANALYSIS}

Gabriella Aguilar Cardozo ${ }^{1}$

Resumo: Mitos de origem são, cionar nosso olhar para as contriantes de qualquer coisa, uma fonte buições africanas para a história histórica da cultura de povos que do mundo e dos povos, essas inrefletem sobre sua origem - seja terrogações seguem o objetivo de essa cosmogônica, geográfica ou sua valorização.

literária. Independentemente de serem fatos históricos comprobatórios ou não, o que se deve e se busca ser aqui analisado, são as co; África.

confluências e intersecções entre eles, onde conversam entre si mitos de origem, por quê se afastam em pontos específicos e quais os possíveis caminhos de fontes primárias de onde beberam. Ao dire-

Palavras-chave: Mito de Origem; Mito Troiano; Mito Bíbli-

Abstract: Origin myths are, above all, a historical source of the culture of peoples who reflect on their origin - be it cosmogonic, geographical or literary. Regar-

1 Licencianda de História pela Universidade Federal Rural do Rio de Janeiro

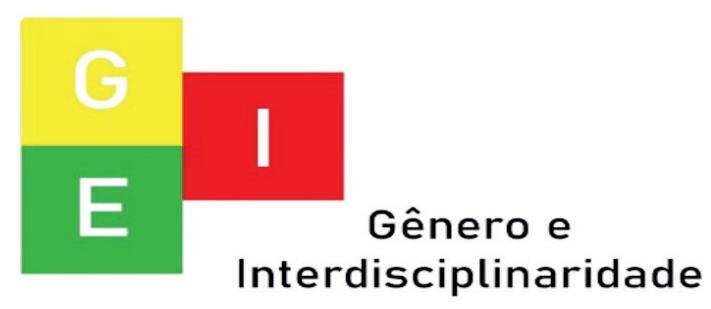


ISSN: 2675-7451

Vol. 02 - n 03 - ano 2021

Editora Acadêmica Periodicojs

dless of whether they are evidential historical facts or not, what should and seek to be analyzed here are the confluences and intersections between them, where origin myths talk to each other, why they deviate at specific points and what are the possible sources of paths primaries from where they drank of. By directing our gaze to African contributions to the history of the world and of peoples, these questions follow the objective of their valorization.

Keywords: Origin Myth; Trojan Myth; Biblical Myth; Africa.

\section{INTRODUÇÃO}

Analisar mitos de origem de diferentes povos requer, antes de tudo, uma consciência histórica que garanta equidade de relevância para com aqueles que foram subjugados frente a outros, que, por sua vez, foram estimulados pela sobrepujança de discursos silenciadores manifestados através de múltiplas marcas de violência. O objetivo do trabalho que se segue, é, para além de apresentar e analisar mitos de origens de povos indígenas nativo-americanos, europeus e judaico-cristãos, sinalizar a contribuição africana não reconhecida para a formação desses povos originários tanto pelo viés populacional concreto, quanto pela herança cultural intrínseca demonstrada nesses mitos.

Partindo desse princípio, é importante salientar que dentre a maioria das referências buscadas para a construção desse levantamento, se apresenta a valorização do mito não enquanto fonte histórica de fatos pelo curso da existência humana (como já o foram), mas sobretudo, como

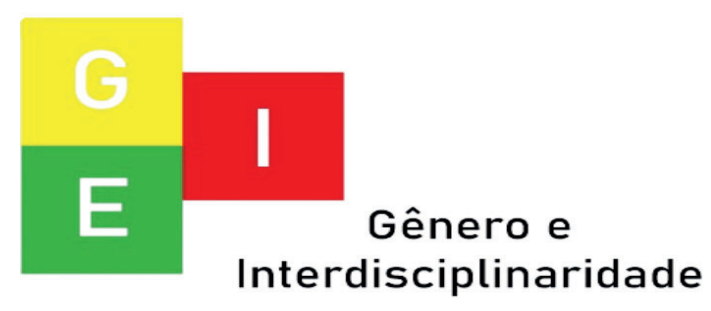


ISSN: 2675-7451

Vol. 02 - n 03 - ano 2021

Editora Acadêmica Periodicojs

fonte histórica dos aspectos que funcionam como marcador cultural de cada segmento existente. Contudo, reunindo agora tais estudos encontrados em meio a pesquisa de publicações acadêmicas ao conhecimento engendrado ao longo do referido curso de História da África, podemos inferir também esses mitos enquanto fonte histórica do esvaziamento cultural promovido contra os povos africanos.

\section{MITOS SATERÊ MAWÉ DOS MUNDURUKU, BAMBARA DO KOMO}

Dando início à proposta que se segue, o debate se encabeça pelo mito de origem do povo Saterê Mawé, que habita o meio da costa do rio Amazonas e a fronteira entre Amazonas e Pará. Esta última localização pertence à seção desse povo denominado etnia Munduruku, a que se refere mais diretamente a citação do seguinte mito:

“...A'at e o Waty, estes representando o Sol e a Lua, são frutos da Cobra-Grande, a poderosa fundante do povo Mawé, a Mói Wató Mağkarú Sése, a grande sucuri que deu o poder de vida ao novo Atapy (Universo) dos mawé, relacionando-se com Tupana (o deus do Bem) e Yurupary (o deus do Mal). Para os mawé, os deuses Tupana e Yurupary, que guardavam e doavam o bem e o mal ao universo e aos homens, não conheciam o dualismo dos sentimentos até descobrirem a traição da Cobra-Grande, que se relacionava com um de dia e com outro durante a noite. Das relações com a Sucuri Sése, surgem o planeta das Águas

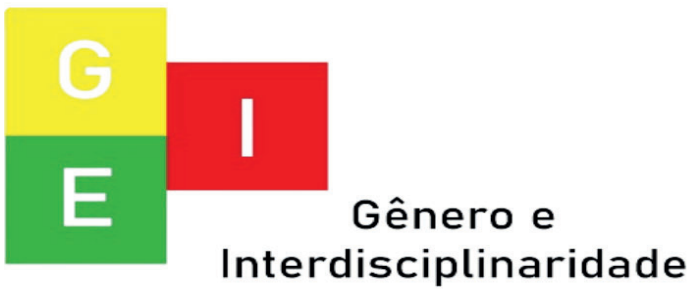


ISSN: 2675-7451

Vol. 02 - n 03 - ano 2021

Editora Acadêmica Periodicojs

e o planeta Terra que

eram povoados por

várias criaturas guia-

das pelos Painí-Pajés

(regidos por Tupana)

e pelos Pajés-Poxy

(regidos por Yuru-

pary). Esses guardi-

ões do deus do bem e

do deus do mal con-

duziram, segundo o

autor, a fecundação

dos sentimentos con-

trários, como a triste-

za e a alegria, a ami-

zade e a inimizade, o

bem e o mal em si, no mundo. Na cosmologia mawé existem dois momentos de criação do mundo, mas só no segundo persiste a vida humana na Terra, que passa a ser finita durante a pajelança que se faz para a Grande Cobra. O Painí-Pajé dos Encantados usa as cores da natureza: o vermelho retirado da força luminosa do urucum desenha o sol do universo; o car- vão investe-se da cor

preta para inspirar as

“forças telúricas"; do açafrão amarelo, os encantados lembram a importância da espiritualidade para a coesão do mundo; junto ao branco da argila, esses seres promovem a paz e a tranquilidade e, por fim, o jenipapo azul, para "captar as energias do céu"." (JARRO, et al. 2020)

Um próprio indígena Munduruku define seu povo enquanto:

“A gente é cultura da palavra. A palavra para nós tem sentido. A palavra para nós tem alma, tem vida. A palavra enobrece, ou também detona, ela derruba, destrói. Então saber usar a palavra para tratar o outro é sinal de inteligência. É sinal de humanidade. É sinal

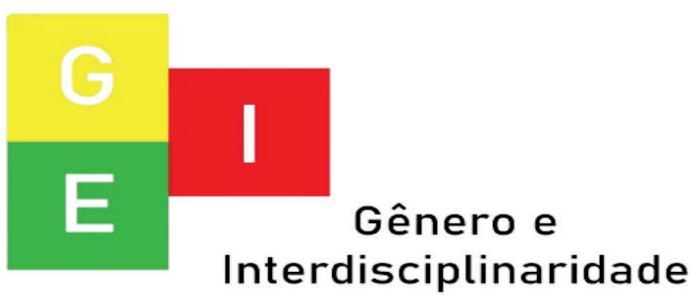


ISSN: 2675-7451

Vol. 02 - n 03 - ano 2021

Editora Acadêmica Periodicojs

de tolerância com o outro." (JARRO, et al. 2020)

Deste modo, é inquietante se colocar diante de tais citações Munduruku sem mover-se em direção às similitudes com os pilares marcantes de culturas africanas. Em primeiro lugar, é percebido na narração do seu mito de origem uma profunda ligação com a natureza, onde esta adquire um caráter mágico-religioso comum capaz de concentrar e mover forças que atuam direta e ativamente na vida humana e, portanto, seu tratamento é feito com respeito e esperança de que, ao se utilizarem dela, receberão as forças de que demandam para executar determinadas tarefas.

Bem como a essa "cultura da palavra" que é viva, engrandece e arruína, também é erigida uma profunda ligação en- tre o homem e a palavra, como uma relação de comprometimento devido a seu poder de criação e destruição. Não apenas na frente individual, mas com toda a coesão social voltada a ela, com grande valor moral e caráter sagrado.

Em "A tradição viva", de A. Hampaté Bâ (HAMPATÉ, 1981), ao tratar sobre a tradição bambara do Komo, busca ambos aspectos -quer dizer, da reverência à natureza e à sacralidade da palavra - no próprio mito de origem africano. Neste caso, "a palavra é uma força fundamental que emana do próprio homem" (HAMPATÉ, 1981), que, por sua vez, é uma criatura com parte de todas as forças de conhecimento existentes com a herança direta do poder do criador Maa Ngala:

"Como provinham de Maa Ngala para o homem, as palavras eram divinas porque

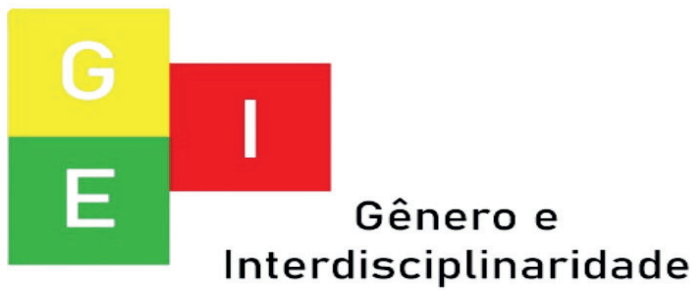


ISSN: 2675-7451

Vol. 02 - n 03 - ano 2021

Editora Acadêmica Periodicojs

ainda não haviam

entrado em contato

com a materialidade.

[...] A tradição africa-

na, portanto, concebe

a fala como um dom

de Deus. Ela é ao

mesmo tempo divina

no sentido descen-

dente e sagrada no

sentido ascendente."

(HAMPATÉ, 1981)

Voltando à natureza, a

menção anterior às "forças telúricas" no mito Munduruku demonstra o tratamento da terra como um real ser vivo que emana sua própria energia afetando plantas, animais e homens; e da mesma forma, o referido autor também resgata tal semelhança quando retrata essa cultura em:

"Uma vez que se considera a natureza como viva e animada pelas forças, todo ato que a perturba deve ser acompanhado de um "comportamento ritual" destinado a preservar e salvaguardar o equilíbrio sagrado, pois tudo se liga, tudo repercute em tudo, toda ação faz vibrar as forças da vida e desperta uma cadeia de consequências cujos efeitos são sentidos pelo homem." (HAMPATÉ, 1981)

A análise destas comparações apresentadas não se baseia em escolhas ao acaso de duas culturas semelhantes. Ao contrário, não se deve tratá-las como duas culturas isoladas em si mesmas com pontuais traços em comum, mas deve-se percebê-las enquanto pertencentes a uma mesma linha ancestral que se ramificou e derivou ao longo de seu curso, sim, entretanto que ainda está em contato com suas heranças africanas vindas de milhares de anos carregando consigo tradições culturais matrizes

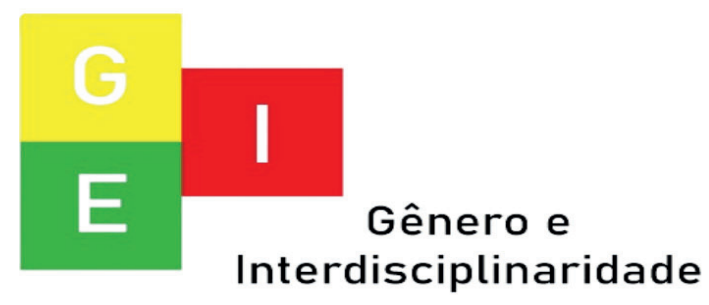


ISSN: 2675-7451

Vol. 02 - n 03 - ano 2021

Editora Acadêmica Periodicojs

que ainda podem ser percebidas. mentos sobreditos, pois, segun-

do esta obra, há um marcador

ÁFRICA COLONIZADORA genético comum entre italianos,

finlandeses e índios americanos,

A mencionada linha an-

onde o denominador comum

cestral referencia a noção históri-

mais recente possui mais de dez

ca que percebe a África enquanto

mil anos. Ou seja, aquilo que une

primeira e fundamental coloniza-

a genética de povos tão distantes

dora do mundo; de que os primei-

geograficamente é a migração de

ros seres humanos a decidirem se grupos africanos e o que os se-

levantar e ir em busca de diferen-

para é a fragmentação em dife-

tes condições para viver ou novas

rentes rotas ao longo do tempo.

opções a se explorar vieram de

O autor alinha os fatos de que há

lá; que todos os seres humanos

quinze mil anos ocorrera o recuo

possuem, em algum nível, genes

da era do gelo e, em seguida, há

que o liguem às terras africanas $\mathrm{e}$

catorze mil anos, se finda o pro-

toda a ideia que conceitua raças

cesso de colonização do mundo

e nacionalidades nasce milhares

com a chegada de uma determi-

de séculos de distância do fun-

nada rota migratória na América

damento primordial anterior co-

do Sul, o último território a ser

mum à toda humanidade: viemos

todos do mesmo lugar.

conquistado. Dito isto, não devia

ser surpresa o apontamento de

É com este embasamen-

que $90 \%$ dos índios com cromos-

to reunido por Nayan Chanda

somo $\mathrm{Y}$ possuem gene indicativo

em "Sem Fronteira" (CHANDA, da linhagem siberiana com mais

2011) que se justifica os argude 22,5 mil anos (CHANDA,

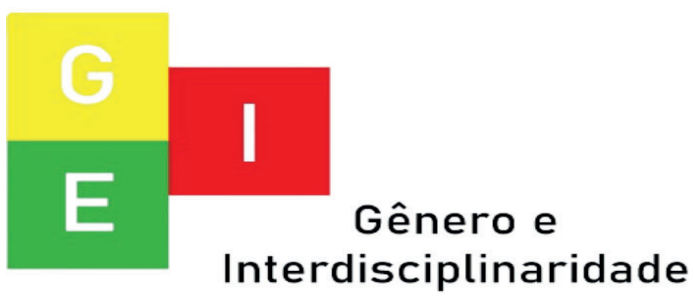


ISSN: 2675-7451

Vol. 02 - n 03 - ano 2021

Editora Acadêmica Periodicojs

2011).

O título do artigo reme-

Desse modo, igualmente te aos argumentos do autor que se desdobram os mitos de origem discorrem principalmente sobre de vários povos europeus. Ainda que não se trate propriamente de uma cosmogonia como nos casos anteriores, muito se diz sobre a forma na qual os mitos de origem nacionais influem sobre a visão dos povos acerca de si próprios e suas consequências sociais e políticas. Como as nações europeias se enxergam no presente concerne à reivindicação dessas identidades e no direito natural à terra, independente se seus mitos de origem evocam fatos históricos ou não. Esses mitos dizem respeito à essência dos homens e desempenham papel vital nas políticas identitárias da atualidade, como foi percebido por Patrick J. Geary em "A Europa das Nações ou a Nação Europa: Mitos de Origem Passados e Presentes" (GEARY, 2013). aqueles povos responsáveis pela queda e fragmentação do Império Romano, chamados de bárbaros pelos helenos e pela historiografia hegemônica, mas que se auto-denominavam responsáveis por resguardar a verdadeira identidade romana, já desgastada, segundo os mesmos. A respeito dessa "verdadeira identidade" se apresentam problemáticas elaboradas com o olhar da Reforma Protestante sobre esse período na disputa pela memória de origem: seria essa singular, homogênea e linear, englobando a totalidade da Europa com a ideia de Nação, sugerindo uma descendência comum e união orgânica de homens em lealdade recíproca.

Em um tipo de confluência reducionista com os estudos de Nayan Chanda, o autor

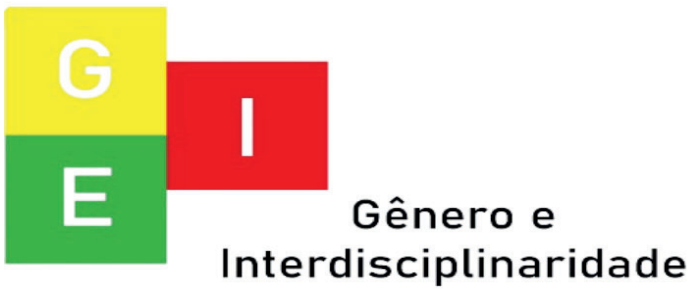


ISSN: 2675-7451

Vol. 02 - n 03 - ano 2021

Editora Acadêmica Periodicojs

recorre à Teoria de Migração dos

Povos de Wolfgang Laz (apud

LAZ, 1557) para apontar as incongruências dessa perspectiva europeia. No entanto, a partir daquilo já exposto por este primeiro é possível delinear a proposta de Geary com o adendo de que o autor não resguarda à autoridade do povoamento do mundo ao Levante africano, iniciando seu debate com questionamentos muito posteriores aos concretos acerca da legitimidade das origens europeias. Utilizando fontes primárias do século XVI e se baseando na mentalidade europeia da época, este historiador estadunidense limita seu debate a migrações germânicas para justificar a heterogeneidade desse recorte geográfico, sem diligenciar qualquer menção a quem de fato o originou.

MITO TROIANO E JUDAI-

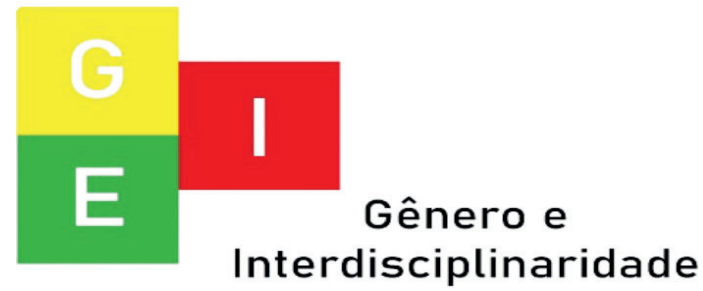

\section{CO-CRISTÃO}

Nesse sentido, buscando se afastar da noção pejorativa incorrida às origens bárbaras, o mito troiano remonta não apenas à origem dos francos, como também ao sentimento de origem comum da civilização pan-europeia, como chama Geary, "sendo um mito de origem unificador poderoso para ancestralidades alternativas" (GEARY, 2013). O mito troiano garante a irmandade ancestral mítica entre francos, macedônios e romanos. Estas culturas europeias, mesmo à contragosto, associam sua origem à alteridade resultante do império romano com as invasões germânicas, se afastando ao máximo destes últimos com mitos de origem que os aproximem o quanto possível da presteza troiana.

Se já existe uma rejeição àqueles tidos como bárbaros, 
ISSN: 2675-7451

Vol. 02 - n 03 - ano 2021

Editora Acadêmica Periodicojs

é ainda mais latente a facilidade de se imaginar a desassociação a sua origem africana; quando, na verdade, Nayan Chanda traça a trajetória migratória M173: fragmentação do Levante ocorrida há mais de trinta mil anos como marcador definitivo dos europeus. Isso se segue devido à experiência com o frio dos eurasianos adquirida na Ásia Central, que os levaram em direção à Europa povoando uma vasta região (CHANDA, 2011).

Outra condição do mito de origem troiano é sua justaposição ao Cristianismo enquanto suporte para um esquema classicizante da cultura comum. Aqui se relatava a história da dispersão dos povos depois do Grande Dilúvio, convergindo com a destruição da Torre de Babel. Ou seja, “juntas, estas duas tradições, a clássica e a bíblica, representavam os modos fundamentais de perceber e classificar os povos durante a Idade Média" (GEARY, 2013). Patrick Geary também se vale das etnografias de Heródoto, onde é possível perceber um tipo de esquema comum aos mitos de origem:

"é, em primeiro lugar, um relato da origem da família real, mas também de um povo. Um primeiro humano, com origens semi-divinas, torna-se o pai de todo um povo, ao mesmo tempo que as divisões entre os diferentes membros deste povo são explicadas como descendentes dos diferentes filhos do fundador." (GEARY, 2013)

É possível aplicar essa fórmula tanto no mito troiano quanto no próprio mito bíblico, no qual "Noé teve três filhos: Sem, Cam, e Jafé. É aos seus

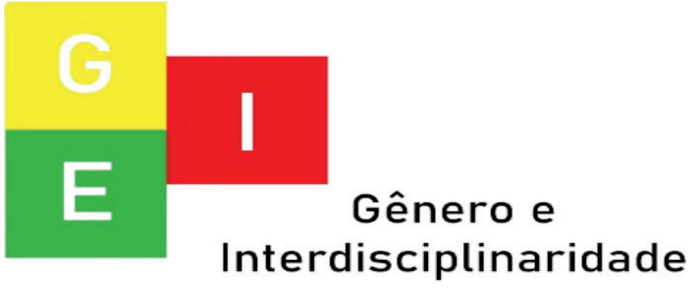


ISSN: 2675-7451

Vol. 02 - n 03 - ano 2021

Editora Acadêmica Periodicojs

descendentes que são depois atribuídas as origens dos povos conhecidos" (GEARY, 2013). O que se conclui disso é que esses mitos de origem são usados para aproximar a sociedade moderna europeia das elites francas e civilização romana; principalmente entre os cristãos que buscavam se distanciar daquela identidade bárbara, para então difundirem a noção do "populus christianus", lê-se: "as diversas "nationes" eram, cada vez mais, percebidas como não mais do que subgrupos do grande "populus christianus", o povo cristão, que segundo a perspectiva eclesiástica romana deveriam ser governados por Roma (GEARY, 2013).”

Por conseguinte, assumindo os emblemas da visão cosmológica bíblica, a mesma desassociação à origem africana ocorre no caso da origem do monoteísmo e, consequentemente, do mito de origem bíblico:

"No princípio, Deus criou o céu e a terra. A terra era vazia e sem forma, a escuridão cobria o oceano primitivo e o espírito de Deus como que adejava sobre a superfície da água. Deus disse então: «exista a luz. E a luz existiu... Deus disse: que a terra produza toda a espécie de animais... E assim aconteceu: Deus fez toda a espécie de animais selvagens, de animais domésticos e animais pequenos. E Deus viu que isso era bom. Por fim Deus disse: «façamos o homem à nossa imagem e semelhança. Que ele mande sobre os peixes do mar, sobre as aves do céu, sobre os grandes animais da terra e sobre os animais pequenos que se movem e rastejam sobre a terra. Foi as-

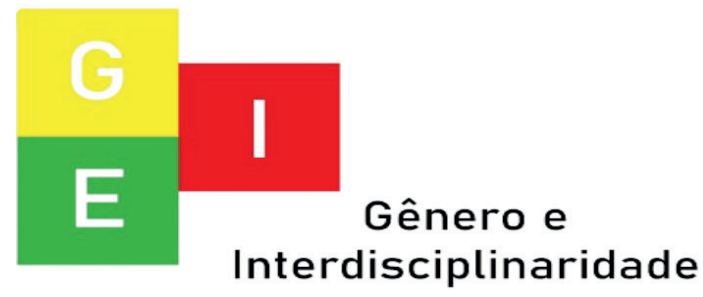


ISSN: 2675-7451

Vol. 02 - n 03 - ano 2021

Editora Acadêmica Periodicojs

sim que Deus criou o homem à sua imagem. Criou-o à sua semelhança. Criou-os homem e mulher. Depois abençoou-os dizendo-lhes: crescei e multiplicai-vos, povoai e dominai a terra...” (PRIESTER CÓDEX).

"O Senhor Deus tomou então pó da terra e fez daí um homem: insuflou-lhe nas narinas o sopro de vida e o homem começou a viver." (PRIESTER CÓDEX).

$\mathrm{O}$ historiador A. Augusto Tavares menciona essas citações em seu trabalho "A criação do homem nos mitos das origens" (TAVARES, 1978), onde, juntamente da apresentação dos mitos cosmogônicos do Egito e Mesopotâmia, demonstra mais que meras semelhanças ou inspirações, mas sim ser inadmissível que os hebreus que deram forma literária ao livro de Gênesis pudessem ignorar tais civilizações dada sua magnitude e impacto no mundo antigo.

Apesar deste autor unir ambas territorialidades para se referir a um Oriente Próximo, acredito ser mais correto afirmar que o deslocamento de mapas é construído a base de ideologias e, ainda que seu direcionamento argumentativo leve a comprovar as influências e alteridades bíblicas bebidas de fontes egípcias e mesopotâmicas, sua colaboração é incompleta. Oriente Próximo é uma designação historiográfica utilizada em casos onde se enxerga relutância ou discordância ao admitir que o Egito faz parte da África e que, portanto, fora de lá que saiu tais inspirações que passaram a compor o livro de Gênesis.

Outrossim, sobre esta

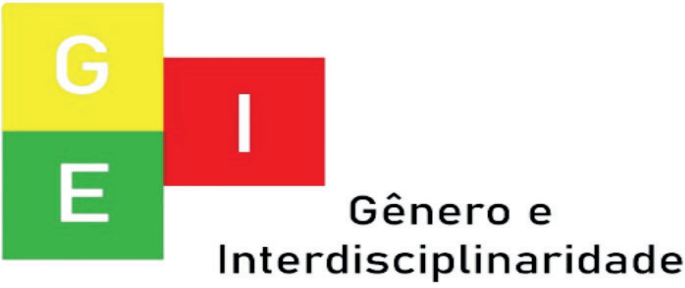


ISSN: $2675-7451$

Vol. 02 - n 03 - ano 2021

Editora Acadêmica Periodicojs

mesma corrente historiográfica, Próximo) como mais uma medihá mais uma designação caracte- da restritiva da consciência das rística de egiptólogos e historia- contribuições de africanos na dores num geral que se denomina civilização da história da huma"monolatria". Este conceito pronidade. Logo, já tendo admitido move a ideia de que, em 1395 a.c., a relevância das crenças egípcias quando o Egito sofreu as reformas religiosas estabelecidas pelo faraó Akhenaton e foram proibidos os cultos a todos os deuses que constituíam o politeísmo egípcio, restringindo-se apenas ao deus Aton, não se instituíra um monoteísmo -chamando de monolatria ao invés. Tal diferença se basearia na noção de que os demais deuses não desapareceram da crença popular e, apesar da forte intolerância religiosa proibitiva, a ausência de cultos não é suficiente para caracterizar um monoteísmo.

No presente trabalho, mais nos interessa a problematização do conceito de monolatria (assim como o de Oriente para compor o mito de origem bíblico, podemos estender a essa argumentação a máxima de que a história judaica é a parte da histórica africana que fora apropriada pelo cristianismo, sendo excluída do mérito de compor uma das maiores religiões do mundo.

Será Freud a resgatar todo o caminho percorrido por Moisés na "libertação" dos hebreus no Egito, em "Moisés e o Monoteísmo" (FREUD, 1990).

Dentre toda a extensa e detalhada exposição, são elucidados diversos pontos argumentativos que convergem na ideia de que a imagem de Moisés com sua origem e ascensão foi construída para que fosse lembrado como herói;

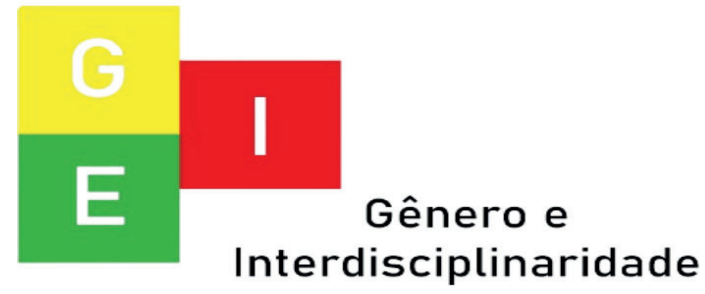


ISSN: 2675-7451

Vol. 02 - n 03 - ano 2021

Editora Acadêmica Periodicojs

mas que na verdade era egípcio

e já viera de algum extrato social enobrecido que liderara de fato um grupo de judeus, mas que, ao contrário do que se acredita, não eram escravos e sim servos remunerados ainda que minimamente para a construção das obras faraônicas (FREUD, 1990).

Entendendo-se que Moisés era egípcio e levando em conta os levantamentos de Freud, se percebe a proximidade de sua vivência com as reformas mencionadas de Akhenaton. Devido a breve duração de 17 anos, tais reformas foram não só anuladas como a religião por ele promulgada, banida. Seguindo essa mesma linha, esse fora o motivo para a peregrinação de Moisés junto daqueles que se atraíam por suas palavras e objetivos. Portanto, encerrando esse ciclo argumentativo, em retrospecto concluiu-se o pertencimento do Egito à
África, as reformas de Amenófis

IV (ou Akhenaton) como precursoras do monoteísmo, Moisés enquanto egípcio alinhado a essas reformas e a perseguição dessas após a morte do faraó como motivação para a partida migratória. Por fim, o mais importante: a retificação da origem monoteísta como parte das exportações africanas para o mundo.

\section{Considerações Finais}

Por fim, buscou-se neste levantamento unir diferentes mitos de origem, sendo estes indígena, europeu e judaico-cristão, para que se pudesse fazer uma análise sob luz dos silenciamentos promovidos acerca das participações do continente africano na história da humanidade. Finalmente, a real compreensão abraça seu início para muito antes do século XV com as Gran-

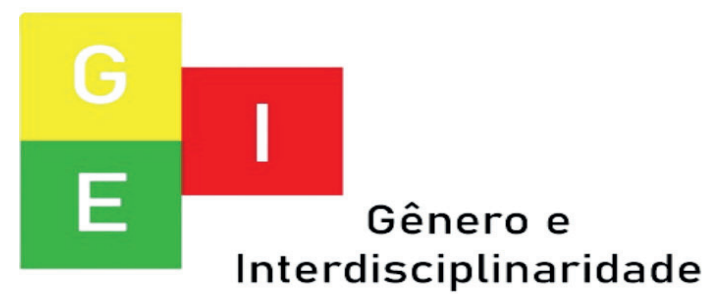


ISSN: 2675-7451

Vol. 02 - n 03 - ano 2021

Editora Acadêmica Periodicojs

des Navegações e subsequente história da escravidão. A ausência de protagonismo da história da África trata-se de um projeto de reducionismo para a forma tal que os enxergamos; que por sua vez, deve ser combatido pela substituição de fontes hegemônicas eurocentradas por aquelas que trazem novas perspectivas com visões pouco promovidas, como assim foram traçadas as argumentações propostas.

\section{Referências Bibliográficas:}

A Bíblia. (GÊNESIS, 2:4b).

BA, Hampaté. História Geral da África I: Metodologia e Pré-história Africana. A tradição viva. Paris: UNESCO. 1981.

CHANDA, Nayan. Sem fronteira. Os comerciantes, missionários, aventureiros e soldados que moldaram a globalização. São Paulo, Record, 2011. (capitulo 1) Freud, Sigmund. Moisés e o Monoteísmo. Lisboa: Relógio d’Água Editores. 1990.

GEARY, Patrick J. A EUROPA DAS NAÇÕES OU A NAÇÃO EUROPA: Mitos de Origem Passados e Presentes. Revista Lusófona de Estudos Culturais, [s. 1.], n 1, v. 1, p. 21-35, 2013.

JARRO, Bianca, et al. Narrando mitologias indígenas: uma experiência em educação. International Studies on Law \& Education, Colégio Luterano São Paulo, v. jan-abr 2020, ed. 34, p. 189-202, 2020.

MUDIMBE, Valentin Y. A invenção de África. Gnose, filosofia e a ordem do conhecimento. Luanda, Pedago, s/d.

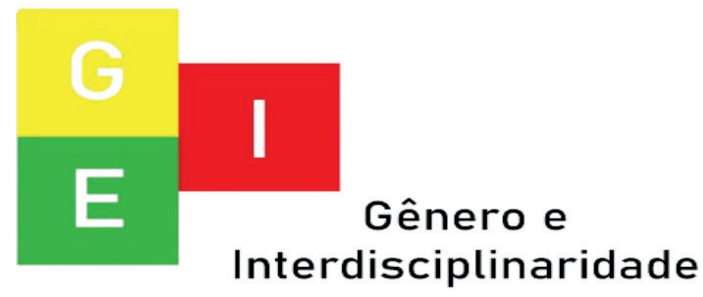


ISSN: 2675-7451

Vol. 02 - n 03 - ano 2021

Editora Acadêmica Periodicojs

Primeira página da Bíblia. Atri-

bui-se à fonte $\mathrm{P}$ («sacerdotal», do

Priester Codex).

TAVARES, A. Augusto. A cria-

ção do homem nos mitos das ori-

gens. Didaskalia, v. 8, n. 1, p. 35-

53, 1 jan. 1978.

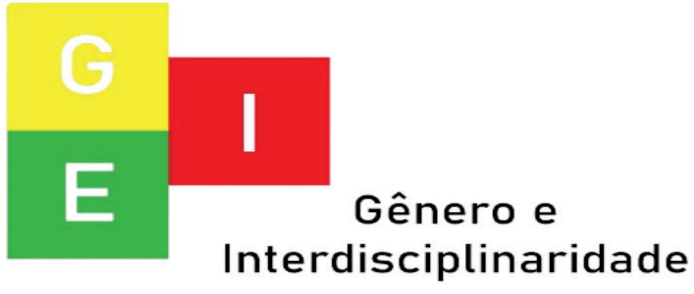

